Est Ag 47 (2012) 553-582

\title{
Religión, democracia y laicidad
}

\author{
MANUel FernáNDEZ DEL RIESGO*
}

RESUMEN: La religión ha sido una constante en la vida de los seres humanos y de los pueblos. Pero ante el fenómeno sociocultural y político de la secularización, entendido como la autonomía de la sociedad y del Estado con relación a la autoridad y control religiosos, la religión tiene que volver a encontrar su ubicación social. Ello exige huir de las dos versiones del fundamentalismo: la religiosa (integrismo clerical), y la laica (laicismo). La religión tiene su cabida en una sociedad democrática, que se identifique con la laicidad. Es en este ámbito donde la religión puede encontrar un protagonismo como una de las instituciones otorgadoras de sentido, y como fuerza remoralizadora.

SUMARIO: Laicidad positiva frente a laicismo negativo. La laicidad positiva, una exigencia de la democracia. El papel de la ética civil y de la moral religiosa en la sociedad secularizada. Los posibles desencuentros.

PALABRAS CLAVES: Religión, ética, democracia, secularización, laicidad, laicismo.

ABSTRACT: Religion is a constant element in people's and individual's lives. But there is a recent phenomenon of socio-cultural and political detachment from society and states, from authority and control. Therefore religion has to recover its social place. That requires avoiding two different versions of fundamentalism: religious (fundamentalist clergy) and secular

\footnotetext{
* Universidad Complutense de Madrid.

riesgo@filos.ucm.es
} 
(laypersons). Religion has a place in a democratic society when identifies itself with secularism. In this realm religion can find a privileged place as one of the institutions able to give sense and able to strengthen morality as well.

SUMMARY: Positive against negative secularism. Positive secularism, a requirement for democracy. Role of civil ethics and religious moral in a secularized society. Possible disagreements.

KEYWORDS: Religion, ethics, democracy, secularization, laypersons, layman.

\section{Laicidad positiva frente a laicismo negativo}

Como afirma O. González de Cardedal, la cultura humana, a lo largo de la historia, se ha desarrollado, entre dos coordenadas, la transformación de la naturaleza y la adoración del Misterio. Pero a partir de la modernidad, se inició un proceso, que acabó por desestimar en gran medida a la segunda. Y es que con la modernidad, se reconoció la autosuficiencia del hombre secular para construir un mundo de vida social puramente inmanente, sin necesidad de tener que acudir al referente divino. La razón ilustrada y la ciencia moderna parecían bastarse para construir un orden moral, político y social, y procurar los recursos materiales, que podían garantizar una vida humana digna y feliz, individual y socialmente hablando.

Todo ello ha propiciado el proceso de la secularización. Éste último es un término que deriva de "secular", que procede a su vez del latín "saeculum" (siglo o mundo). Pero sin querer detenernos ahora en otras disquisiciones etimológicas ${ }^{1}$, entenderemos por secularización un proceso socioestructural que, a la larga, ha afectado notablemente al conjunto de la vida cultural e ideológica, y que ha significado una progresiva desaparición de los símbolos religiosos de integración y legitimación cultural. Ello quiere decir que la sociedad y la cultura se han ido "liberando" del control y tutela de la autoridad religiosa, de sus instituciones y de sus símbolos. Se ha ido dando una "retirada de la religión" de su tarea de imponer-aportar a la

${ }^{1}$ Cfr. FERNÁNDEZ DEL RIESGO, Manuel, ¿Secularismo o secularidad? El conflicto entre el poder político y el poder religioso, Madrid, 2010, pp. 17ss. 
sociedad una estructura legitimadora del mundo y del poder político ${ }^{2}$. Proceso que se inició con las teorías contractualistas con relación al origen del Estado, desde Hobbes, pasando por Locke, Spinoza, y Rousseau (aunque éste hablara de una "religión civil", como elemento reforzador de la conciencia ciudadana), hasta Kant, sin olvidar la trascendencia histórica de la Revolución Francesa de 1789. Da la impresión, como afirmó el teólogo Dietrich Bonhoeffer, que "Dios pierde terreno", y que el hombre "se las arregla bastante bien sin Él"3. Y es que la religión no parece ejercer ya directamente un influjo sobre sectores y estructuras sociales, tales como el gobierno, las empresas económicas, y demás organizaciones civiles; y, por su parte, la explicación científica y la manipulación técnica se imponen eficazmente y de un modo inmediato en el tratamiento de determinados fenómenos y problemas. En fin, dicho de modo coloquial, "secular" es lo referente al mundo, a la realidad espacio-temporal, a lo intrahistórico. Un ámbito además, donde el ser humano asume, con su correspondiente riesgo e incertidumbre, su autonomía responsable.

Junto al término "secular" o "secularización", también se ha utilizado el término "laico" o "laicidad". Estos términos provienen del griego "laós", que significa pueblo. Es sinónimo de otro, "dêmos", del que deriva el término "democracia". El matiz diferenciador está en que mientras que el segundo remite a la idea de un pueblo en un lugar determinado, el primero hacer referencia, especialmente, al hecho de la "reunión", al hecho de reunirse. Y así, una sociedad laica o secular es aquella regida por el pueblo, y no por otros poderes externos, ya sean mágicos o sagrados. "Laicidad" es, pues, un término que remite a la idea de la autonomía de un pueblo soberano, que se autogobierna, y, en último término se identificaría con la defensa de lo humano 4 . Aunque el término "secular" parece aludir más bien a lo social y cultural, y el término "laico" más al ámbito de lo políticoinstitucional (separación del Estado y de la autoridad religiosa), en nuestro caso, nos vamos a permitir la licencia de utilizarlos como sinónimos, y para referirnos al hecho básico de la pérdida de la hegemonía social de lo religioso, y a la autonomía de la realidad humano-social y política.

Ahora bien, dentro del ámbito de la secularización, actualmente es conveniente, al menos a mi modesto juicio, hacer una distinción entre secu-

2 Cox, Harvey, La ciudad secular, Barcelona 1968; BERGER, P.L., Para una teoría sociológica de la religión, Barcelona, 1971; GAUCHET, M. La religión en la democracia El camino del laicismo, Madrid, 2003.

${ }^{3} \mathrm{Cfr}$. BONHOEFFER, Dietrich, Resistencia y sumisión. Cartas y apuntes desde el cautiverio. Salamanca, 1983, p. 228.

${ }^{4}$ Cfr. GonZÁlez FAus, José I., La difícil laicidad, Barcelona, 2005, pp. 5-6. 
laridad-laicidad y secularismo-laicismo. El segundo, que también podríamos definir como laicismo negativo o excluyente, viene a ser una concepción de la realidad cerrada a toda trascendencia. Implica la pérdida del sentido religioso, que se concretará, bien en indiferentismo, esto es, en el rechazo de la actitud religiosa de una manera precrítica, o bien en agnosticismo y ateísmo. Un secularismo que, a veces, llevado por su celo, adopta una actitud agresiva y no respetuosa con los derechos de los demás (libertad de pensamiento, de conciencia, etc.), al concretarse en un ateísmo militante, que, de modo disimulado o abiertamente hostil, aspira a toda costa a que la religión sea borrada del mapa social, por considerarla algo inútil, aún más, dañina. Considera superflua toda referencia a la Trascendencia, y busca, por ello, la posibilidad de deslegitimar los derechos de la religión, y que ésta quede relegada a la vida privada como residuo arcaico a extinguir. En este sentido suele traducirse en "una estrategia común en círculos de progresistas que pretende erosionar no sólo la presencia de organizaciones o ideas religiosas en la vida pública, sino cualquier propuesta de sentido relacionada con las confesiones religiosas en general o, en nuestro país, la Iglesia católica en particular"5. Para este secularismo-laicismo, serán modernas y seculares aquellas sociedades "que dejan al arbitrio privado las cuestiones religiosas y dejan en manos de las autoridades políticas las cuestiones de ciudadanía". Por contraposición, serán reaccionarias e integristas "aquellas sociedades que no se someten a los imperativos de una razón científica, ilustrada y moderna con capacidad para la separación, abstracción y subordinación de todas las dimensiones de la vida humana a su dimensión política"6. Con ello se pretende una "ruptura esquizofrénica" entre la vida pública y la vida privada, olvidándose que el individuo humano es uno, y deberá procurar una armonía y coherencia entre las diversas facetas de su vida personal y social, sin renunciar por ello a la especificidad de las mismas. Frente a este planteamiento excluyente debe hacerse una matización. Evidentemente, en un sociedad democrática y plural, se puede ser agnóstico o ateo, y en el libre juego de la sociedad civil, llevado por el convencimiento sincero de que el ateísmo es necesario para el desarrollo de un mejor humanismo, asumir iniciativas y compromisos, de cara a la expansión de dicho convencimiento. Pero su argumentación no debería basarse en análisis-evaluaciones reduccionistas e unilaterales, y planteamientos que disimulen su verdadera intención. A este respecto, resulta

5 Domingo Moratalla, Agustín, Ciudadanía activa y religión, Madrid, 2011, p. 63.

${ }^{6}$ IBIDEM, op. cit., pp. 11-12. 
inquietante, por ejemplo, el modo cómo el PSOE entiendió el concepto de laicidad, tal como se refleja en el Manifiesto político que publicó con motivo del XXVIII aniversario de la Constitución de 19787. Allí se resalta a la laicidad como "garantía de unificación y orden", debiéndose a ella "la existencia de conciencias libres y críticas". Evidentemente los sistemas políticos tienen que organizarse conforme al principio de laicidad, tal como aquí lo venimos entendiendo. Pero da la impresión de que el mencionado Manifiesto quiere hacerlo extensible a la misma sociedad civil de un modo reduccionista, al establecer una estrecha relación entre la laicidad y las virtudes cívicas, sin explicitar que éstas últimas, son "anteriores al principio jurídico de la laicidad". Debemos de tener en cuenta que la laicidad del Estado es, por supuesto, una condición necesaria para hacer viable un sistema democrático, al hacer posible un espacio público de diálogo en libertad, pero no es una condición suficiente, sin más, que garantice la altura moral que puede necesitar una sociedad. No podemos olvidar, que ese espacio público es el propio de las diversas tradiciones culturales y religiosas, que deberán de nutrir dicho diálogo. Este lamentable "olvido" de las tradiciones culturales y religiosas, que anidan en la sociedad civil, y que pueden ser portadoras de humanidad, hace sospechoso al mencionado Manifiesto, de querer aspirar a que la sociedad civil sea, no simplemente autónoma o laica, sino laicista en el sentido negativo y excluyente. Lo que olvida el secularismo-laicismo es que no podemos confundir o hacer equivalente la secularización del Estado con la secularización de la sociedad civil. La laicidad se debe de entendèr como un principio de organización política, pero no de organización social, pues en la vida social, el individuo no es sólo ciudadano (miembro de una comunidad política), sino que también puede ser miembro de una empresa laboral, de una asociación civil, de una comunidad religiosa, etc. Según el Manifiesto, da también la impresión de que las creencias religiosas son un impedimento para la construcción de la democracia, al carecer el creyente de una suficiente libertad y capacidad crítica al estar supeditado a un orden superior o heterónomo. Pero esto significa reducir la fe y las experiencias religiosas a puro fundamentalismo-integrismo ${ }^{8}$. En cambio, la secularidad-laicidad, que también podríamos definir como laicidad positiva e incluyente, entiende que la realidad humano social, es el ámbito donde se desenvuelven las conciencias libres y responsables de los seres humanos, en busca del ideal de la vida buena y feliz, y

\footnotetext{
${ }^{7}$ Cfr., "Constitución, laicidad y educación para la ciudadanía". www.psoe.es

8 DOMINGo Moratalla, Agustín, op. cit., pp. 94-96).
} 
donde debe darse un diálogo respetuoso y tolerante entre todos, para ir consensuando soluciones a los retos y problemas a los que nos enfrenta inevitablemente la vida. Secularidad o laicidad positiva e incluyente es, pues, como dice González Faus, búsqueda del bien común, que hace viable la convivencia pacífica. En el fondo, descansa en la experiencia o conocimiento connatural del valor y la dignidad de todos los seres humanos. En este sentido no es extraña al ideal del humanismo. Un concepto que, como dice Pedro Aullón, promueve la elevación humana desde la ética y la cultura, procurando el respeto a la vida y al espíritu, y que hoy resulta tan necesario para orientar los grandes retos y posibilidades que nos ofrecen las modernas tecnologías y los problemas de la convivencia social. Humanismo y laicidad positiva constituyen una gran ocasión para recuperar el protagonismo de la reflexión ética y política, y ser fuente de esperanza de cara a la posibilidad de vivir juntos, atareados en la construcción de un destino común. Una laicidad democrática, abierta y dinámica, frente a una laicidad de combate, ofensiva contra los creyentes, que busca la posibilidad de vivir juntos en armonía, gracias al descubrimiento de unos valores comunes de la sociedad, pero respetando el pluralismo y la diversidad. Y lo más interesante es, que esta secularidad, o laicidad positiva puede ser asumida y defendida por una "religión ilustrada" (entiéndase la que ha sabido dialogar con la ilustración). Como nos recuerda Habermas, frente al fundamentalismo religioso "que se aparta del mundo moderno o se vuelve hacia él de una forma agresiva", la religión ilustrada es "una fe reflexiva que se relaciona con otras religiones y que respeta las conclusiones falibles de las ciencias institucionalizadas, así como los derechos humanos"9. Ella entenderá la secularidad como una concepción y una actitud que, reconociendo la relativa autonomía del mundo y del hombre en la historia, la hace compatible con una concepción religiosa que descubre la presencia y acción de Dios en dicho mundo y en dicha historia, invitando al hombre a la aventura de la salvación. En línea con esta concepción, ha afirmado el profesor Martin Velasco, que sólo debería de tener futuro una religión que "pueda ser vivida por un sujeto consciente de su subjetividad individual, respetuoso de su autonomía y atento a su inalienable dignidad"10. La secularidad o laicidad positiva e incluyente, por tanto, puede ser asumida, valga la aparente paradoja, desde una perspectiva religiosa, como la legitimación, desde los propios presupuestos de la fe, de una justa mundaneidad, de una justa

9 HABERMAS, Jürgen. TAYLOR, Charles. Butler, Judith. WEST, Cornel, El poder de la religión en la esfera pública. Madrid, 2011, p. 129.

10 Martin Velasco, J., Metamorfosis de lo sagrado, 1998, Santander, p. 37. 
desacralización (o reconocimiento de la relativa autonomía de lo humanosocial), y de una justa emancipación. Esto permite, como ha hecho el presidente de Francia Nicolás Sarkozy, hablar incluso de una laicidad al servicio de las religiones, que promueven una esperanza, que movilizan para la prosecución del bien común, y que no resultan enemigas de la República, al ser portadoras de valores morales ${ }^{11}$. Ello, desde luego, ha exigido una revisión crítico-hermeneútica de la propia religión. En este sentido, el paso por la crítica racional-ilustrada, y "la filosofía de la sospecha" (P. Ricoeur), ha servido para desposeer a la religión de morbosidades, y arbitrariedades, y purificar y fortalecer las propias convicciones religiosas. Un "re-significación", que coadyuva a la "depuración de lo sagrado". Una desmitificación que sirve para potenciar la carga simbólica del lenguaje religioso, y posibilitar su "re-encantamiento post-crítico." Una hermeneútica que nos ayuda a recuperar el símbolo, como dice Ricoeur, "en su calidad de signo originario de lo sagrado". Una nueva interpretación que profundiza en la comprensión genuinamente religiosa ${ }^{12}$. A ello coadyuvó, por ejemplo, el ya mencionado pastor luterano Dietrich Bonhoeffer, asesinado por los nazis, que planteó, en sus famosas cartas desde el cautiverio, la necesidad de vivir, desde la fe, la autonomía del mundo profano.

Desde luego es difícil que, en una sociedad tan plural y compleja como es el caso de la nuestra actualmente, donde observamos una diversidad de mentalidades, todos los ciudadanos vayamos a coincidir totalmente en nuestras concepciones y valoraciones. Estamos, pues, abocados necesariamente a buscar puntos de encuentro. $\mathrm{Y}$ el plus cualitativo del cristiano, reside en su creencia en que en ese juego de encuentro dialogal de conciencias y libertades, se hace presente el reino de Dios, que le convoca, y le invita a la conversión y al compromiso liberador del pobre. Ello significa que el cristiano está llamado a vivir religiosamente lo profano, a vivir la dimensión sacramental de lo secular (González-Carvajal). De tal manera que para él "la historia de la salvación" se juega en medio de nuestra historia cismundana. En este sentido, el cristianismo es una religión laica, pues a Dios se le encuentra especialmente en el hombre (él es la hierofanía preferida por el Dios del Profeta de Nazaret), en la medida en que lucha contra lo que le deshumaniza y esclaviza ${ }^{13}$.

11 Cfr. Sarkozy, N., La Republique, les religions, l'espérance, Paris, 2004, 17-19. Cit. Domingo MORATAlla, Agustín, op. cit. pp. 121-122.

12 Domingo Moratalla, Agustín, op. cit., pp. 179-182.

13 Cfr. FERNÁNDEZ DEL RIESGO, Manuel, op. cit., 2010, 32-45; CASTILlo, J.M. /TAMAYO, J. J., Iglesia y sociedad en España, Madrid, 2005, pp. 72, 76; PAGOLA, José Antonio, Jesús. Aproximación histórica, Madrid, 2008. 


\section{La laicidad positiva, una exigencia de la democracia}

Para seguir profundizando en la conveniencia de esta reivindicación, que defendemos, de una secularidad o laicidad positiva e incluyente, vamos a hacer una consideración de la misma, desde la perspectiva de la política. $\mathrm{Y}$ es que es muy importante, frente a los excesos del secularismo o laicismo negativo y excluyente, y a los de un integrismo religioso o clericalismo confesional, proclive a una sacralización excesiva, caer en la cuenta de que la laicidad positiva es consustancial con un estado democrático, defensor de un estado de derecho, y con una sociedad multicultural.

El ser humano es social por su naturaleza, de tal manera que necesita vivir en una colectividad, que se dota de una autoridad política al servicio de la misma, propiciando su cohesión y organización. Autoridad que desde luego se entenderá como secular o laica, pues dimana de la misma naturaleza de la colectividad. El sujeto político en que se institucionaliza dicha autoridad política es el Estado, aunque éste no agote toda la vida y las manifestaciones públicas de la comunidad. No podemos olvidar que la vida social también se manifiesta en las diversas actividades económicas, profesionales, educativas, religiosas, etc., que precisamente el estado secular o laico deberá de proteger y asegurar jurídicamente, en pro del bien común, y de las libertades personales. En este sentido, sostenemos que la secularidad o laicidad positiva e incluyente está al servicio de los derechos humanos y del bien común, y que el presupuesto del carácter absoluto e inalienable de la persona humana, es el fundamento de la democracia y de dicha laicidad positiva. La secularización o laicización de la modernidad ilustrada, significó que la persona conquistó un protagonismo central en las relaciones políticas y sociales, que antes quedaban, de un modo excesivamente directo, sometidas a la divinidad.

La sociedad democrática y plural necesita, de un modo consustancial, de una secularidad o laicidad positiva bien entendida, que no es sino aquella que se identifica con la existencia de un espacio público y libre para el concurso respetuoso y dialogante de todas las ideologías, modos de pensar y creencias en búsqueda del bien común. Ello es hoy más necesario que nunca en una sociedad plural y multicultural, donde juegan distintas autorreprensentaciones del fenómeno humano y de la misma sociedad, que deben dialogar entre sí, en busca del "mejor argumento". Es una exigencia de justicia, que tiene que ver o está relacionada con los derechos de la ciudadanía, que no son sino los derechos humanos. La secularidad o laicidad positiva es, pues, una consecuencia de los derechos humanos, y garantía, a su vez, del respeto a los mismos. Sin la secularidad o laicidad positiva se 
haría inviable el ordenamiento democrático y autónomo de la sociedad. Y es que la libertad de la secularidad es la misma con la que se identifica la democracia: la ausencia de privilegios para cualquier creencia (o ideología) con relación al poder político. De ahí la inevitable separación entre el poder político y la autoridad religiosa.

Ahora bien, en el seno de esa sociedad democrática y laica, esto es autónoma y autosuficiente, habrá ciudadanos, que encontrarán una última fundamentación y significado de carácter religioso a su existencia y compromisos humanos y sociales, y otros que no. Es algo que corresponderá a la libérrima intimidad personal de cada ser humano. Es por ello por lo que la autoridad secular, bien entendida, carece del legítimo derecho para impedir una visión religiosa de la vida, que las personas, tanto individual como socialmente, pueden tener como fruto de su libre opción. El exceso erróneo del secularismo o laicismo negativo es impedir la posibilidad de "la comprensión religiosa de la vida política", como lectura última de la misma, que legítimamente pueden sostener algunos ciudadanos; como el exceso del confesionalismo clerical es pretender que la única visión válida del compromiso político es la que dimana de la interpretación religiosa, no aceptando la posibilidad de una lectura del mismo puramente humanista. Ambos son incompatibles con la libertad. Por contraposición, la secularidad o laicidad positiva, desde la perspectiva política, pone entre paréntesis la creencia o increencia de los ciudadanos, porque es respetuosa con los Derechos Humanos, y por tanto, con la libertad de pensamiento y de conciencia, y porque sabe que no es competencia de la política definir, en términos de última radicalidad, la verdad y el sentido de la existencia humana. El Estado secular o laico bien entendido, no toma postura en materia religiosa. Cosa que no ocurre con un Estado laicista, proclive a una cierta animadversión hacia la religión, más o menos disimulada, o abiertamente hostil hacia la misma. Se trata, como dice González Faus, de "una prescindencia respetuosa". Como ha señalado Teófilo González Vila, "el truco del laicista supone presentar la negatividad propia de su particular opción (...) como si fuera la propia de la actitud general de neutralidad religiosa que debe guardar el Estado. (...) No es lo mismo no-profesar-religión-alguna que profesar-el-no-a-toda-religión. Paradójicamente, el Estado laicista no es un Estado laico, puesto que no sería aconfesional, no sería religiosamente neutral"14. El estado laico es aquel que permite y propicia que todos los

14 GONZÁLEZ VILA, T., "Aconfesionalidad, laicidad y laicismo. Una clarificación necesaria”. En DOMINGo MORATALlA, A. (coord.), Ciudadanía, religión y educación moral, Madrid, 2006, pp. 54-55. 
ciudadanos puedan ejercer su libertad de pensamiento y de conciencia, de cara a adoptar determinadas actitudes, ya sean creyentes, agnósticas, o abiertamente ateas. La política secular y democrática, en principio, no tiene que estar legitimada desde una militancia creyente o atea, sino sólo desde unas premisas puramente humanistas. Es decir desde unas consideraciones antropológicas y unas estimaciones morales. Descansa en las exigencias políticas que derivan de la dignidad humana; y que no son sino la defensa de los Derechos Humanos, solemnemente proclamados, entre otras ocasiones, en la Asamblea General de las Naciones Unidas (10-12-1948).

Es por ello por lo que habrá que recordar al ateo y al hombre de fe, que deberán de comprender que sus opciones tienen que ser ofertadas, en el diálogo y con el testimonio, no impuestas de modo coactivo, pues sin libertad responsable, y sin reflexión crítica, se desvanece la posibilidad de una vida humana digna de ser vivida. Como sostiene con razón Juan José Tamayo Acosta, los derechos del creyente y del ateo o agnóstico merecen idéntico respeto. Todo lo demás es caer en formas de intolerancia que impiden a creyentes y ateos el derecho a pensar por cuenta propia.

Consideramos, por lo tanto, que son el creyente ilustrado y el increyente humanista, los que pueden defender la democracia, ya que son ellos los que defienden los principios morales básicos, y los argumentos que hacen posible la convivencia inteligente y honesta. Por esta razón urge cultivar un diálogo entre la fe religiosa y la fe ilustrada, y afirmar que el cristianismo no está en contra de la democracia y su consustancial laicidad, siempre que el Estado no se arrogue una doctrina sobre el sentido último del enigma humano. Con lo que no deberán de estar de acuerdo, tanto creyentes ilustrados como increyentes humanistas, es con el secularismo-laicismo, ya que, paradójicamente, traiciona a la laicidad en su propia esencia.

Es cierto que las relaciones del Estado y la Religión, en ocasiones, pueden estar presididas por el disenso, o por la presencia de concepciones contrapuestas respecto a alguna cuestión de especial trascendencia. (Pensemos, por ejemplo en cuestiones de bioética). Pero ello no impide una convivencia y un respeto, que incluso, a medio o largo plazo, pueden ser fecundos, si el Estado y la institución religiosa, saben jugar su papel respectivo. No obstante la presencia de la buena voluntad, a veces las relaciones se degradan de modo preocupante, y pueden convertirse en fuente de crispación y descalificación. La clave, para deshacer dichos malentendidos, es establecer la nítida separación entre el ejercicio de la autoridad política y de la religiosa de un modo respetuoso. Y ello quiere decir que ninguna de dichas autoridades debe pretender decir la última palabra en la esfera o el ámbito que le compete a la otra, en el sentido de pretender anularla o sus- 
tituirla. El pluralismo cultural y ético de la actual sociedad democrática exige, en principio, la tolerancia y el respeto mutuo como valores éticos.

La sociedad democrática y plural tiene que permitir y proteger la libre circulación de las diversas concepciones antropológicas, éticas, y religiosas, que se dan en la sociedad civil, como "placenta nutriente", a partir de la cual, el diálogo podrá alumbrar cotas de consenso, que se concretarán en la acuñación de una "ética civil", como referente necesario a la hora de articular un estado de derecho. No podemos olvidar que la ética cívica, cuyo espíritu debe orientar la tarea legislativa, y ésta misma, se irán construyendo, revisando y rectificando, a partir del debate parlamentario, cuyos miembros deberán tener su "cordones umbilicales" conectados con los partidos políticos, la opinión pública, el saber de los especialistas, y las diversas instituciones de la sociedad civil, incluidas, por supuesto, las religiosas. Esa ética civil o de mínimos, no es sino un conjunto de orientaciones de valor y de principios básicos, sin los que el ideal de la humanidad se nos desdibuja, pudiéndosenos convertir, en la práctica, en una burla, o lo que es peor, en una afrenta intolerable. La ética civil, como tarea social y política, supone la conquista por parte de la sociedad de una convergencia fundamental a la hora de pensar lo humano y sus exigencias de realización en el tiempo, en la sociedad, y en la historia. Esa ética civil vendrá a constituir un a priori, una fuente pre-política de la vida democrática, que alimentada por varias tradiciones culturales y religiosas, no podremos ya olvidar nunca. Esto, como observa atinadamente el profesor Agustín Domingo Moratalla, nos debe llevar a distinguir siempre, entre lo legal y lo moralmente legítimo, no confundiendo "la validez moral de una norma con la legalidad que la ha promovido". De lo contrario caeríamos en el relativismo fáctico de un positivismo ético-jurídico vulgar, fácilmente manipulable por el pragmatismo partitocrático. En nuestro caso, "La ética mínima que hizo posible la Constitución fue el resultado de tradiciones morales que se fueron filtrando y decantando donde había muchos elementos de máximos religiosos, morales o simplemente humanistas"15. Ello nos recuerda que la ética civil no agota la moralidad de los ciudadanos, que pueden asumir, y de hecho muchas veces las asumen, las llamadas "éticas de máximos", que se identifican con ideales de perfección y de felicidad, que pretenden dar razón de la moralidad en toda su complejidad, y que cada grupo ofrece, a partir de sus propias experiencias éticas, estéticas y religiosas. Como muy bien ha puntualizado José $\mathrm{M}^{\mathrm{a}}$ Setién, no le compete al Estado pronunciarse sobre la concepción última del bien y del mal y de la felicidad humana, sino instru-

15 Domingo Moratalla, Agustín, op. cit., p. 93. 
mentar medidas legales de cara a la continua e inacabable prosecución del bien común ${ }^{16}$. Entenderemos por éste último la plasmación práctica, según las circunstancias y las posibilidades, de los derechos y deberes fundamentales, que vehiculan la solidaridad y la justicia ${ }^{17}$. Y quizás lo más interesante es que ese diálogo, al que hemos aludido, puede ser beneficioso tanto para los mínimos como para los máximos éticos, esto es, "para que los mínimos se alimenten de los máximos y para que los máximos puedan purificarse desde los mínimos"18.

\section{El papel de la ética civil y de la moral religiosa en la sociedad secularizada}

Para seguir profundizando en el alcance de esta laicidad positiva que defendemos, debemos de seguir reflexionando, aunque sea brevemente, sobre el papel de la ética civil y el de las éticas religiosas, en el seno de una sociedad democrática y plural. Ello encierra una nueva forma de plantear el diálogo entre la fe y la razón, una nueva forma de profundizar en las posibles relaciones y vínculos entre religión y moral, que pueden ser fecundas, y que nos hace pensar que "la relación entre lo sagrado y lo secular está cambiando". Con ello tendrá que ver una concepción hermeneútica de la moral, que no tiene necesariamente que traducirse, como en el caso de Richard Rorty, en darle más importancia a la democracia que a la moral, ni en renunciar, sin más, a la metafísica, como en el caso de Habermas. No se trata de quedarse en una mera moral de situación de la que nos habla una narrativa democrática, ni en un "sujeto abstracto y ahistórico del laboratorio" (Habermas). Naturalmente, la hermeneútica recupera la importancia del lenguaje, de la conversación, y del contexto, pero no tiene por qué quedarse en el nivel cognitivo de los conceptos, sino que reivindicando "la dimensión interrogativa del lenguaje" y "el valor del dialogo", aspira a la búsqueda de la verdad, situándose en "un nivel raciovital o íntegramente personal donde no están en juego sólo las ideas o los valores como entidades ideales, sino la realidad radical de la persona humana. No sólo como un ser que habla o se comunica sino como un ser preocupado por el sentido o valor de lo que va a ser él cuando se está comunicando". Además la hermenéutica reivindica las posibilidades del diálogo, pero no como mero instrumento de consenso coyuntural, sino de potenciación de una apropiación

16 Cfr. SEtiÉn, José Ma , Laicidad del Estado e Iglesia, Madrid, 2007.

17 Cfr. FERNÁNDEZ DEL RIESGO, Manuel, op. cit., 2010, pp. 71-77, 88-92.

18 Domingo Moratalla, Agustín, op. cit., p. 13. 
crítica, que más allá de la sospecha, se abre a una voluntad de sentido y a una esperanza, que vuelve a replantear las relaciones entre la razón y la fe, entre lo profano y lo sagrado. Con ello tendrá que ver una tarea de interprètación y traducción, que abunda en la intelección. Y ello nos lleva a la conclusión de que "la modernización y la secularización no han terminado con la religión"19.

En la construcción de la ética civil no deberá ser despreciada, en principio, ninguna fuente testimonial y de información. Todas las concepciones de las diversas instituciones y grupos orientadores de sentido, o "centros de elaboración del pensamiento teórico y práctico", ya sea la Iglesia Católica, otras religiones, partidos políticos, movimientos sociales y culturales, etc., deberán ser escuchadas y valoradas como "ofertas en libertad" 20 Desde estos presupuestos, se comprende que la ética civil, frente a la secularistalaicista o la integrista-fundamentalista, será laica, es decir estará abierta, y se dejará iluminar por todas las fuentes de inspiración, incluidas las religiosas. Sin el diálogo plural, respetuoso y crítico, que profundice en los contenidos de esa ética civil, no será posible la superación razonable de los conflictos, de cara al acuerdo básico. Lo que no es de recibo, y es del todo rechazable, es la crispación, el insulto, la descalificación a priori como fruto del prejuicio, y la ridiculización malintencionada, de los que, a veces, dan testimonio, tanto miembros del gobierno, y de nuestra clase política, como algunos militantes del integrismo religioso. El laicismo negativo y excluyente, como reconoce el propio Habermas, empobrece las posibilidades del diálogo en nuestra sociedad.

Curiosamente el filósofo alemán ha evolucionado en su reflexión sobre la religión y su posible protagonismo social. Algo que no valoró en sus planteamientos iniciales. En su Teoría de la acción comunicativa ${ }^{21}$ defendió la tesis de que la función de integración social, que en la sociedad tradicional corría a cargo de la religión, ahora debería corresponder a la razón comunicativa, de tal manera que el acuerdo racional debería de sustituir a la autoridad religiosa. Planteamiento, pues, coherente con la realidad de la sociedad secularizada. No obstante, ya en las décadas de los 70 y de los 80 , más de una vez, sugirió que no convendría renunciar a "cierta comprensión y transmisión del potencial de las tradiciones religiosas". Y más tarde, cuando desarrolla su "pensamiento postmetafisico", no deja de reconocer que es necesario tener en cuenta y no olvidar lo religioso "para

19 Domingo Moratalla, Agustín, op. cit., pp. 72, 139, 140, 141, 145, $14 \dot{6}$.

20 Cfr. SETIÉN, José. M ${ }^{\mathrm{a}}$., op. cit., 2007.

${ }^{21}$ HABERMAS, J., Teoría de la acción comunicativa, I y II, Madrid, 1987. 
comprender los conceptos fundamentales de la historia del espíritu", y que en la religión se encuentran contenidos semánticos "que pueden ser importantes para la correcta modelación de las sociedades modernas". Habermas, al respecto, no tiene inconveniente en reconocer la compenetración del cristianismo y la metafísica griega, que no sólo sirvió para expresar la idea del creacionismo judío en términos del paradigma griego, convirtiendo al logos en punto de unión entre la filosofía griega y la teología judía, teniendo lugar una fusión entre la causa primera de aquella y la libertad creadora de la segunda, y la elaboración del cuerpo dogmático de la teología cristiana, sino también para dar a luz un amplio cuerpo de conceptos entre los que cabría recordar términos como "responsabilidad, autonomía y justificación, historia, memoria, reinicio, innovación y retorno, individualismo y comunidad". Ello no ha significado, a la postre, sino "una apropiación de contenidos genuinamente cristianos por parte de la filosofía". Es ilegítima, pues, una autocomprensión secularista de la filosofía, que la considere simplemente como "la adversaria natural de la religión" 22 . En el discurso que pronunció cuando los libreros alemanes le concedieron el Premio de la Paz (2001), reconoció que la clásica teoría de la secularización estaba ya superada, porque nuestra sociedad seguía manteniendo un diálogo con la religión, y ello porque, entre otras cosas, la religión seguía siendo un recurso moral, porque las convicciones religiosas pueden ser portadoras de convicciones morales 23 . Y posteriormente, ha vuelto a reconocer, contraponiéndose en este punto al planteamiento de Hans Blumenberg, que "El desarrollo occidental ha sido configurado por la continua apropiación que ha hecho la filosofía de los contenidos semánticos de la tradición judeocristiana, y es una cuestión abierta si este proceso de aprendizaje que ha durado siglos puede continuar o incluso si todavía no ha terminado24". Sobre todo porque las religiones pueden ser fuentes de valores que coadyuven al fortalecimiento de la ética ciudadana, que tanto necesita una sociedad multicultural como la nuestra. De manera explícita ha insistido

22 HABERMAS, J., “¿Fundamentos prepolíticos del Estado democrático?”. En RATZINGER, J. HABERMAS, J., Dialéctica de la secularización, Madrid, 2006, pp. 42, 116. Cfr., HABERMAS, J., Israel y Atenas: ensayos sobre religión, teología y racionalidad, Madrid, 2001, p. 185, HABERMAS, Jürgen, “¿Una sociedd mundial postsecular? En HABERMAS, Jürgen. TAYLOR, Charles. BUTLER, Judith. WEST, Cornel, Madrid, 2011, p. 135.

23 Cfr. REDER, M. / SCHMIDT, J., "Habermas y la religión". En HABERMAS, J. / Reder, M. /SCHMIDT, J., Carta al Papa. Consideraciones sobre la fe, Barcelona, Buenos Aires, México, 2009, pp. 25ss, 29, 39.

24 HABERMAS, Jürgen, "Lo político: el sentido racional de una cuestionable herencia de la teología política". En HABERMAS, Jürgen. TAYLOR, Charles. BUTLER, Judith. WEST, Cornel, op. cit., p. 36. 
últimamente en que, "Aunque la religión no puede ser reducida a moralidad ni ser equiparada a orientaciones éticas, mantiene viva, sin embargo, la conciencia de ambos elementos"25.Esto no significa que Habermas haya renunciado a la autonomía del liberalismo político de cara a una justificación de los fundamentos normativos de un Estado democrático y constitucional $^{26}$. Así, por ejemplo, en el preámbulo de una ley aprobada por el parlamento de un estado soberano, no procede justificarla remitiendo a una fiosofía atea, o a presupuestos teológicos. Lo que ocurre es que, curiosamente, su discurso ahora no finaliza aquí, pues su sentido de la observación, le hace tomar conciencia de la degradada realidad social actual, de la pérdida de sentido de nuestra llamada "sociedad avanzada". Ello le lleva a reconocer la conveniencia de recuperar el bagaje moral (intuiciones morales), que se conserva en las religiones (ideales de justicia y de vida buena, libertad y dignidad humana, etc.). Habermas está convencido de que "en el público secular puede muy bien haber intuiciones morales sepultadas que un discurso religioso conmovedor puede hacer aflorar. Cuando uno escucha a Martin Luther King, no importa si eres creyente o no. Entiendes lo que quiere decir"27.Las religiones conservan fuentes de cohesión social y de solidaridad prepolíticas. Por ello, la religión puede venir en auxilio de la razón moderna; a modo de catalizador, para que ésta supere el desánimo y derrotismo que padece. Basta recordar el discurso postmoderno y su "pensamiento débil", o la "razón perezosa"28. Ciertamente los ciudadanos, en la medida en que no sólo son, al menos en teoría, coautores de las leyes democráticamente establecidas, sino también destinatarios de las mismas, deberán de ser consecuentes con ellas en sus acciones y compromisos. Sin embargo la experiencia nos enseña, que la fidelidad en la práctica no se asegura, sin más por vía legal. En la vida diaria hacen falta las virtudes morales y políticas. Y se puede dar, como de hecho él denuncia, un "desmoronamiento de la solidaridad ciudadana", que tiene que ver con el "privatismo" y la "despolitización". El discurso práctico, debilitado por el relativismo y el pesimismo nihilista, está como desprestigiado, no motivando suficientemente a los actores sociales, no "levantando el ánimo" tan necesario para el éxito del compromiso práctico. Frente a la presión del discur-

25 IBIDEM, op. cit., p. 37.

26 Cfr. HABERMAS, J., Entre naturalismo y religión, Barcelona, Buenos Aires, México, 2006, p. 108; HABERMAS, J., “¿Fundamentos prepolíticos del Estado democrático? En RATZINGER, J. / HABERMAS, J., op. cit., 2006, pp. 27, 34.

27 HABERMAS, Jürgen. TAYLOR, Charles. BUTLER, Judith. WEST, Cornel, op. cit., p. 65 .

28 Cfr. Argullol, R. y TRÍAS, E., El cansancio de Occidente, Barcelona, 1992. 
so publicitario, con su carga de consumismo hedonista, y su "fraudulenta felicidad mágica", esta modernidad "descarriada" necesita asegurar el aprendizaje y el ejercicio práctico de los principios y valores, mediante el concurso y la influencia recíproca del pensamiento liberal-ilustrado y de las tradiciones religiosas ${ }^{29}$. El proceso cognitivo no garantiza, sin más, el éxito práctico de los derechos fundamentales. Éste último necesita algo más que mera razonabilidad. Habermas, es sensible, por influencia kantiana, a la insuficiencia del intelectualismo moral. De ahí que la fides cristiana puede venir en ayuda de la fe racional motivada moralmente. Y las comunidades políticas, ante el desánimo y baja moral, no deberían de despreciar u olvidarse, como afirma Habermas, "de unos recursos de sentido, una solidaridad y una justicia que cada vez escasean más"30.. En este sentido "la moral vivida" en el seno de las religiones, es un capital que no deberíamos dejar de lado, como pretende el laicismo negativo y excluyente. La comunidad religiosa puede ser un agente de socialización moral, que propicie y motive una moral personal vivida en la práctica. Y es que la comunidad religiosa promueve formas de identificación con valores, en el seno de un ideal de vida, que se encuentran en las "éticas de máximos", que refuerzan los sentimientos y motivaciones morales. Así, por ejemplo, Habermas remarca que, históricamente considerado, el ritual de las prácticas de culto, como un nivel de comunicación gestual anterior al lenguaje proposicionalmente diferenciado, "ha sido una fuente de solidaridad social para la que la moral ilustrada de la igualdad de trato con todos no ofrece un verdadero equivalente motivacional" 31 . En la vida comunitaria que posibilita la fe religiosa, hay un potencial de sentido que fortalece las motivaciones morales, de cara al compromiso práctico social y político, que refuerzan el entusiasmo, la ilusión y la esperanza, como arma contra el desencanto y el pesimismo que nos aquejan. Ello significa para Habermas, superar el prejuicio secularista, evitando la reducción cognitiva de la religión (punto de vista epistemológico), para resaltar su lado motivacional, y axiológico. La presencia social de la religión, y este posible protagonismo, le hace pensar a Habermas que la religión se sigue manteniendo "como una configuración contemporánea del espíritu!",y le lleva a hablar, en la actualidad, de una sociedad post-secular, entendiendo por ello, como afirma Eduardo Mendieta, una "situación sociológica", un "hecho socio-cultural". Un hecho socio-

${ }^{29}$ Cfr. HABERMAS, J., op. cit., 2006, pp. 112-113, 244-

30 HABERMAS, J. "Una réplica". En HABERMAS, J. / REDER, M. / SCHMIDT, J., op. cit., 2009, p. 227.

31 HABERMAS, Jürgen. TAYLOR, Charles. BUTLER, Judith. WeSt, Cornel, op. cit., p. 134. 
cultural que también contempla, como ya hemos indicado, la posibilidad de que se establezca un diálogo entre la razón secular y una conciencia religiosa reflexiva e ilustrada.

Para reforzar el argumento habermasiano, recordaremos que la experiencia nos enseña que "Sin proyectos máximos de vida buena, la ciudadanía siempre estará bajo mínimos morales" Y que nos debemos de contentarnos con las meras declaraciones constitucionales y formulaciones de programas gubernamentales, olvidando "lo mejor de cada uno", y las "fuentes de legitimidad moral" 32.

Abundando en la tesis habermasiana de la regeneración moral de una modernidad "descarriada", desde la fe cristiana, podemos decir que la fundamentación última de la moral, que aporta la espiritualidad cristiana y la motivación que ello conlleva, influyen mucho más en la práctica, en la vida moral, que el saber ético estrictamente teórico. O dicho de otro modo, el sentirse amado y perdonado por Dios gratuitamente, puede ser un "plus" que refuerza y anima al compromiso moral, y el esfuerzo por la conversión y rectificación, hasta alumbrar con éxito, por parte de algunos, la excelencia moral, de la que está tan urgida nuestra desnortada sociedad. Excelencia que, como ha señalado Benedicto XVI, se nutre de la vinculación entre fe, esperanza y caridad, que posibilita la convicción firme en el triunfo definitivo, en el fin de la historia, del amor de Dios sobre el mal y la muerte. Un* fe así vivida fomenta la acogida de la gracia, y las capacidades de perdonar sin límites, de reconciliar, de cuidar, de consolar y de "generar una felicidad próxima" 33 . En este caso la ética está reforzada por un fundamento o fondo de convicciones, que proporciona al creyente un sentido que, en su gratuidad, le sobrepasa como don. Así, la racionalidad moral no es anulada, sino enriquecida y fortalecida. En conexión con ello tiene razón Charles Taylor cuando afirma: "Estoy ciertamente de acuerdo en que hay diferencias muy grandes entre el razonamiento ético de una persona hondamente religiosa y el de alguien que no lo es. Hay ciertas concepciones sobre la posibilidad de transformación humana en que unos creen y otros no"34. El propio Habermas ha reconocido que las religiones son especialmente sensibles frente al enigma del mal, del sufrimiento, y de la muerte. Y que la "apocatástasis" o restitución integral, como un "plus" de la

32 Domingo Moratalla, Agustín, op. cit., p. 2011, 54.

33 Cfr. BENEDICTO XVI, 2006, Dios es amor, Madrid, pp. 66-67; FERNÁNDEZ DEL RIESGO, Manuel, Antropología de la muerte. Los límites de la razón y los excesos de la razón, Madrid, 2007, pp. 123-160; 329-339; DOMINGO MORATALLA, Agustín, op. cit. p. 59.

34 HABERMAS, Jürgen. TAYLOR, Charles. BUTLER, Judith. WEST, Cornel, op. cit., 64. 
religión, es una respuesta desde la fe esperanzada, de la que carece todo mesianismo político y la moral ilustrada. Ciertamente sin ese "plus" de la fe queda sin respuesta la deuda contraída con los "vencidos" y los "mártires" de la historia, y sin resolver el dilema, ya señalado por Kant, entre virtud (justicia) y felicidad, cuya conjunción es el "bien supremo". Sin ese plus queda sin respuesta suficientemente satisfactoria la "dimensión catastrófica" de la historia denunciada por Walter Bejamin, o como dice Cornel West: "El amontonarse de restos de naufragio tras naufragio, el amontonarse de escombros, el potencial desperdiciado, la posibilidad no cumplida de personas valiosas" 35 . Algo en lo que ha insistido, por ejemplo, la teología de la "memoria passionis" de J.B. Metz ${ }^{36}$. No obstante, Habermas no da el paso de la fe, y se conforma con las posibilidades argumentativas de su razón comunicativa, renunciando al consuelo religioso, pero ello no le impide esa "recuperación" de la religión como agente coadyuvante para la regeneración moral de la sociedad. De ahí que la las religiones puedan tener un lugar legítimo en la deliberación moral pública. Por ello Habermas ha afirmado últimamente, que "en la medida en que las comunidades religiosas desempeñan un papel vital en la sociedad civil y en la esfera pública, la política deliberativa es producto de un uso público de la razón tanto por parte de los ciudadanos creyentes como de los no creyentes". La sociedad democrática debe de apostar por el uso de "las libertades comunicativas", que hacen posible el mantenimiento de "la marea de los flujos de comunicación pública desde abajo". Y en ese juego tienen un papel legítimo "las comunidades religiosas activas y no fundamentalistas", como "fuerzas transformadoras en el centro de una sociedad civil democrática, especialmente cuando las fricciones entre mensajes religiosos y seculares dan lugar a controversias que estimulan las cuestiones normativas y despiertan la conciencia de su relevancia"37... Por ello defiende que el Estado constitucional y democrático deberá de cuidar "la relación con todas las fuentes culturales de las que se alimenta la conciencia normativa y la solidaridad de los ciudadanos". Junto a ello matiza oportunamente que la "secularización" deberá ser entendida, tanto por el creyente como por el

35 WEST Cornel, "Religión profética y futuro de la civilización capitalista". En HABERMAS, Jürgen. TAYLOR, Charles. Butler, Judith. WEST, Cornel, op. cit., p. 90.

36 Cfr. METZ, J.B., La fe en la historia y en la sociedad, Madrid, 1979, IBIDEM, Por una cultura de la memoria, Madrid, 1999, IBIDEM, Memoria passsionis. Una aproximación provocadora en una sociedad pluralista, Santander, 2007.

37 HABERMAS, Jürgen, "Lo político: el sentido racional de una cuestionable herencia de la teología política". En HABERMAS, Jürgen. TAYLOR Charles. BUTLER, Judith. WEST, Cornel, op. cit., pp. 33-34. 
no creyente, "como un proceso de aprendizaje complementario", que les permitirá tomarse en serio sus aportaciones a la solución de los retos y problemas que afectan a la convivencia social ${ }^{38}$... Naturalmente en ese aprendizaje mutuo, la religión deberá de asumir la exigencia de volverse cada vez más reflexiva, y la filosofía deberá de interesarse por una reconstrucción de los contenidos religiosos mediante un lenguaje racional universal. Hay que tratar, pues, de "traducir" los contenidos de la fe, que lo permitan, al lenguaje de la razón ilustrada. Ello significa que en la religión hay "potenciales semánticos valiosos", que pueden ser aprovechables por toda la sociedad "una vez que liberen sus contenidos de verdad profanos" 39 . Los creyentes tendrán "que aceptar que el potencial contenido de verdad de las afirmaciones religiosas se deben traducir a un lenguaje universalmente accesible, antes de que puedan entrar en el orden del día de los parlamentos, los tribunales o las instituciones administrativas, e influir en sus decisiones". Naturalmente esto implica, a la recíproca, que "los ciudadanos no creyentes están obligados a no descartar por principio las aportaciones religiosas en la formación de la voluntad y de la opinión pública como meramente vacías o sin sentido. Los ciudadanos creyentes y no creyentes deben encontrarse al mismo nivel en el uso público de la razón. Para el proceso democrático, las aportaciones de una parte no son menos importantes que las de la otra"40. Esto permite que el ámbito de lo político, sin renunciar a su sentido racional, no renuncie tampoco a una presencia social de la religión. Todo esto exige que, "unos y otros deben de tomar en serio sus argumentos, unos y otros deben ser conscientes de que los nuevos desafíos éticos de la secularización exigen apertura mutua, reconocimiento y voluntad de aprendizaje social". Se trata de un proceso de aprendizaje mutuo, que nos puede ayudar a avanzar en el desarrollo de razones cognitivas, y que exige, repetimos, tanto de creyentes como de no creyentes, "un esfuerzo de traducción de un lenguaje a otro para hacer públicamente accesibles las aportaciones respectivas" 41 . La necesidad de la traducción parece obvia, en la medida en que será el lenguaje común de la razón secular, el que nos podrá llevar al establecimiento de algún consenso razonablemente argumentado. "Las razones seculares -dice Habermas- no amplían la perspectiva de la comunidad particular de cada uno, pero impulsan una pers-

\footnotetext{
38 Cfr., HABERMAS, J, op. cit., 2006, pp. 116-117.

39 Cfr., IBIDEM, J., op. cit., 2006, pp. 150-151.

40 HABERMAS, Jürgen, "Lo político: el sentido racional de una cuestionable herencia de la teología política". En HABERMAS, Jürgen. TAYLOR, Charles. BUTLER, Judith. WEST, Cornel, op. cit., pp. 35-36.

41 Domingo MORATAlla, Agustín, op. cit., pp., 126, 128).
} 
pectiva común para que diferentes comunidades puedan desarrollar un punto de vista más inclusivo, trascendiendo su propio universo del discurso". Se tratará de traducir "expresiones propias del lenguaje religioso a un lenguaje público que nos permita llegar a razones que son más generales que las del lenguaje original (...); razones que son seculares en el sentido de trascender el dominio semántico de comunidades religiosas particulares" 42 . Sin embargo eso no justifica la conclusión a la que llegó, durante algún tiempo J. Rawls, aunque posteriormente ha rectificado, y que Charles Taylor nos recuerda: "Por tanto, la razón religiosa o bien llega a las mismas conclusiones que la secular, y entonces es superflua, o bien llega a conclusiones contrarias, y entonces es peligrosa y perjudicial. Por eso hay que mantenerla al margen" 43 Frente a ello, Judith Butler afirma que no podemos pensar que cuando una afirmación religiosa se traduce, se extrae de ella lo verdaderamente aprovechable, lo racional, y el resto "se desecha como escoria". Y se pregunta "si los residuos de lo teológico no siguen resonando en lo que nosotros entendemos como secular. (...).Creo (...) que hay (...) versiones de universalidad, de igualdad y de cohabitación que emergen del discurso religioso. No estoy segura de que puedan ser completamente separadas de él". O como observa Taylor, cuando unas "ideas trascienden su ámbito original e inspiran a la gente, y entonces encuentran, quizá, otro lenguaje (...) muchas veces todavía arde la chispa original en ese nuevo contexto" 44 . Es cierto que la traducción es una ardua tarea, pero puede ayudarnos a profundizar en la comprensión de mi concepción y de la del otro, y al descubrimiento de niveles de comunión consensuadora, que enriquezca un "fondo de convicciones". Ello posibilitará que intuiciones profundas puedan "saltar las fronteras de lo religioso a lo no religioso o de lo no religioso a lo religioso". Un proceso de intercambio que, según Taylor, puede ser inagotable 45 ... Habermas reconoce, como ya indicamos antes, que no sabemos si ese proceso de apropiación semántica se ha agotado, o continuará dando frutos. Pero él es partidario de "un cambio de actitud a favor de una relación dialógica, abierta al aprendizaje, con toda tradición religiosa...". Se tratará, como dice Ricoeur, de decir de otro modo el

42 Habermas, Jürgen. TAYLOR, Charles. ButLeR, Judith. WeSt, Cornel, op cit., pp.66, 107.

43 TAYLOR, Charles, "Por qué necesitamos una redefinición radical del secularismo". En HABERMAS, Jürgen. TAYLOR, Charles. BUTLER, Judith. WEST, Cornel, op. cit., p.53.

44 HABermas, Jürgen. TAYLOR, Charles. BUTLER, Judith. WeSt, Cornel, op. cit., pp. $106,109$.

45 TAYLOR, Charles, "Por qué necesitamos una redefinición radical del secularismo", op. cit., p. 105. 
mismo mensaje, que recíprocamente posibilitará la acogida de la palabra del otro. Ello puede ser fuente de mutuo enriquecimiento y de comunión. Pero ello requiere, como observa Cornel West, que el pensador secular intente "tener oído" para la religión, y el creyente "tener oído" para lo secular. Como Habermas repite, esa interacción entre creyentes no creyentes "podría sacar a la luz intuiciones reprimidas, olvidadas, en desuso, que están sepultadas en alguna parte. La interacción puede funcionar en los dos sentidos. En el mejor de los casos, la fuerza racionalizadora de una parte se junta con las poderosas imágenes de un lenguaje luminoso del mundo que viene de la otra". Si la comunicación dialogal tiene éxito, el resultado a lo mejor "no es una traducción estricta", hay algo irreductible en cada lenguaje, pero sí podemos "poner al alcance de todos potenciales semánticos que de otra manera quedarían hundidos en el lenguaje de una particular comunidad religiosa"46. La única duda que puede quedarnos es la que sugiere Craig Calhoun: Habermas recomienda incluir las voces religiosas en la esfera pública, con un criterio puramente instrumental: porque son útiles "mientras implícitamente se duda de que puedan ser verdad" 47 . Sin embargo, bajo mi modesto criterio, no podemos pensar que Habermas esconda o disimule en su argumentación un pragmatismo vulgar. Lo que se decanta de la lectura de sus textos es una valoración positiva de la religión como fuerza moral, poniendo entre paréntesis el contenido estrictamente fiducial y teológico del discurso religioso, aunque esto para algunos no sea tan fácil...

Todo esto significa un planteamiento novedoso por parte de Habermas, que, desde su agnosticismo, no sólo se abstiene de pronunciarse acerca de las verdades específicamente religiosas, sino que contempla ahora, no una razón abstracta sino vinculada con la vida, que le lleva también a reconocer que la religión tiẹne algo que ver con la genealogía de la razón, como ya planteó K. Löwith ${ }^{48}$.

Podemos, por tanto, concluir que Habermas intenta hacer compatible una fundamentación autónoma del Estado y de la vida moral y política, con la conveniencia de la áyuda que la cultura y la espiritualidad religiosas pueden prestar, en la práctica, de cara a la regeneración moral de la sociedad. Concretando, ello significa que la "voz de la religión" deberá ser oída en el diálogo de una sociedad civil democrática y plural, y que, incluso,

46 HABERMAS, Jürgen. TAYLOR, Charles. BUTLER, Judith. WEST, Cornel, op. cit., pp. $132,108$.

47 Calhoun, Craig, "Epílogo". En Habermas, Jürgen. TAYlor, Charles. ButLer, Judith. WEST, Cornel, op. cit., p. 121.

48 Cfr. DOMingo Moratalla, Agustin, op. cit., pp., 150-151. 
deberá de sentirse su resonancia en el debate parlamentario de un Estado soberano. En este sentido tiene el mérito de que, aunque distingue epistemológicamente entre razón y religión, ha acabado por superar, como le reconoce Charles Taylor, "la desconfianza política hacia la religión". Habermas, pues, se identifica con lo que hemos denominado una "laicidad positiva e incluyente", en la que todas las voces coprotagonistas de la sociedad deben ser escuchadas en un diálogo honesto, y respetuoso. Sólo así, afirma Habermas, conseguiremos compartir "un mundo discursivo", "unas creencias comunes", y "construir las bases para crear instituciones y resolver problemas a través del Estado"49.

Charles Taylor, al que acabamos de nombrar, es otro autor, que, dentro de la tradición hermeneútica, también ha planteado un puente entre sociedad moderna y religión, entre lo secular y lo sagrado, pero ahora no de carácter ético-político como es el caso de Habermas, sino de naturaleza ético-cultural. Como Habermas reivindica la presencia de lo sagrado en la esfera pública, como una tarea de traducción en busca de sentido. Y es que a través de "la variación semántica de las categorías", que tiene que ver con una vinculación de los significados con las prácticas, "ha evolucionado la sed de trascendencia que sigue estando culturalmente presente". De tal modo que lo sagrado no ha desaparecido, sin más, sino que está temporalmente ocultado o eclipsado por lo secular ${ }^{50}$. Y es que para este autor, la secularización no se puede interpretar simplemente como la sustracción de la sociedad a la autoridad religiosa, con efectos liberadores. En verdad la secularización es un proceso abierto, que todavía no ha dicho su última palabra, pues hay gente que no se encuentra a gusto, en este mundo. El coste de esta conquista de madurez y autonomía da la impresión de que "ha dejado fuera algo grande, algo importante, que se ha ignorado algún nivel profundo del deseo, que se ha relegado una realidad superior y exterior a nosotros" 51 Ello hace comprensible que pueda haber movimientos de contra-secularización. Es más, hoy hay que reconocer que la separación de la religión de la esfera política, no significa que los ciudadanos dejen de ser creyentes, aunque se reduzcan las prácticas rituales. La opción religiosa sigue siendo una opción personal, aunque muchas veces más allá de la vinculación con la institución: "vagos grupos de identidad", "creyentes sin

49 Habermas, Jürgen. TAYlor, Charles. Butler, Judith. WeSt, Cornel, op. cit., p. 104. Cfr., FERNÁNDEZ DEL RIESGO, Manuel, ¿Secularismo o secularidad? op. cit., 2010, pp. 119-126.

50 Cfr. Domingo Moratalla; Agustín, op. cit., pp. 156-158; TAYLOR, Ch., A secula Age, 2007.

51 TAYLOR, Ch., Las variedades de la religión hoy, Barcelona, 2003, pp. 65. 
Iglesias" (L. Kolakowski), o "religión invisible" ( Th. Luckmann). Se da un pluralismo espiritual en el que se debe respetar a los demás. En nuestra sociedad, pues, coexisten la creencia y la increencia. Además, la religión sigue teniendo que ver con las posibilidades del desarrollo moral ${ }^{52}$. En la sociedad secularizada, las tradiciones morales no se han desentendido del todo de las convicciones religiosas. Los "imaginarios sociales modernos" de la esfera pública tienen que ver con la conformación del orden moral de la sociedad, sin el que ésta última no es viable. $Y$ en la búsqueda de ese consenso, la religión es una fuerza más. "No hay razón para considerar la religión un caso especial, frente a los puntos de vista no religiosos, "seculares" (...) o ateos"53. Hay un secularismo obsesionado con el peligro de la religión, fruto del mito ilustrado (la Ilustración es "un avance absoluto y sin restricción"), que hay que superar, (Taylor lo llama "reliquia del pasado"), que se alimenta del presupuesto epistemológico de que la religión es menos racional que el pensamiento secular, o es un "modo defectuoso de razonar", y que se une a otro de alcance político, su potencial amenaza. Frente a ello, Taylor, en oposición a Habermas, intenta suavizar las diferencias entre las razones seculares y religiosas, recordándonos que la autosuficiencia de la razón moderna no es un bloque monolítico, sino fragmentado en múltiples discursos con fundamentos diversos (Descartes, empirismo, kantismo, etc), que relativiza el rigor del argumento racional, habiendo diferencias últimas, que se encuentran tanto en el discurso filosófico como en el religioso. $Y$ es que la razón esá enraizada en "horizontes de valoración fuertes" que muchas veces no se explicitan. Hay pues, "una especie de inconmensurabilidad" y "unos límites que no son exclusivos de la religión". Ello invita a reconocer que, en la sociedad democrática moderna, muy alejada de las circunstancias políticas y religiosas de la Europa de los siglos XVII y XVIII, hay que tener en cuenta todos los imaginarios que buscan, con sus respectivas versiones, la consolidación de unos valores fundamentales de la sociedad democrática, como son la libertad, la igualdad y la fraternidad. Ello se traduce en un "orden moral moderno", o "filosofía de la civilidad", que se vertebra en tres principios: los derechos y libertades de todos los ciudadanos; la igualdad de todos ellos; y un gobierno legitimado por el consentimiento. Ello significa que esos derechos y libertades deben ser defendidos y disfrutados por todos los ciudadanos sean creyentes o no,

52 Cfr., IBIDEM, op. cit., pp. 102-117

53 TAYLOR, Charles, "Por qué necesitamos una redefinición radical del secularismo". En HABERMAS, Jürgen. TAYLOR, Charles. BUTLER, Judith. WEST, Cornel, op. cit., $\mathrm{p}, 41$. 
aunque cada uno tenga una fundamentación última de los mismos diferentes. Así, por ejemplo, "Un kantiano justificará el derecho a la vida y a la libertad señalando la dignidad del agente racional; un utilitarista hablará de la necesidad de tratar a seres con capacidad de sentir placer y dolor de manera que se maximice lo primero y se minimice lo segundo; un cristiano dirá que los hombres están hecho a imagen y semejanza de Dios. Todos ellos están de acuerdo en los principios, pero difieren en las razones de fondo por las que sostienen esa ética. El Estado debe defender esa ética, pero debe de abstenerse de favorecer cualquiera de las razones de fondo". La pluralidad de la sociedad moderna exige por parte del Estado la neutralidad. Ello significa que, "El Estado no puede ser ni cristiano, ni musulmán, ni judío. Pero por la misma razón, tampoco debe ser marxista, ni kantiano, ni utilitarista. Naturalmente, el Estado democrático terminará aprobando leyes que (en el mejor de los casos) reflejen las convicciones de sus ciudadanos que serán cristianos, musulmanes, etc.: de toda la gama de posturas presentes en una sociedad moderna". Sin embargo, todos los ciudadanos deben estar comprometidos en la maximización o mejor éxito práctico de esa ética democrática. Para reforzar esta responsabilidad, Taylor nos recuerda que la "identidad política", tan necesaria para un estado democrático, remite a principios básicos, como son los derechos humanos y un orden constitucional. Pero ella, en el devenir histórico, no puede desvincularse de una identidad colectiva, que tiene que ver con "tradiciones históricas, lingüísticas o religiosas". Lo importante es que los elementos religiosos y no religiosos de esas tradiciones coadyuven al proyecto común de la convivencia democrática. Y ello no será viable sin procurar un equilibrio entre "libertad de conciencia e igualdad de trato" 54.

En el contexto de esta laicidad positiva, es oportuno valorar también el planteamiento de Benedicto XVI. Para el pontífice, la sana laicidad es aquella capaz de valorar "la aportación de las confesiones religiosas en la construcción de una ciudadanía democrática y mantenga abierta el enriquecedor dinamismo entre mínimos y máximos" 55 . Ante el desgaste de la práctica democrática y la desmoralización generalizada, piensa Ratzinguer que no es descabellado contar dialogalmente con todas las fuentes culturales de la moralidad, incluidas las religiosas. Y dando un paso más en relación con el planteamiento habermasiano, y para profundizar en las causas

54 TAYLOR, Charles, "Por qué necesitamos una redefinición radical del secularismo". En HABERMAS, Jürgen. TAYLOR, Charles. BUTLER, Judith. WEST, Cornel, op. cit., pp., 42, 49, 50-52, 54, 56-58, 104.

55 DOMINGo Moratalla, Agustín, op. cit., p. 14. 
de fracaso práctico, nos señala que la razón viva y existencial no es la abstracta, sino la que se ha desarrollado en formas históricas, aliada muchas veces con la fe. En el discurso que el Pontífice escribió, pero que no pudo pronunciar por causa de los laicistas intolerantes, en la Universidad $L a$ Sapienza de Roma $(16,01,2008)$, frente a una racionalidad ahistórica, volvió a recordarnos la importancia de esa sabiduría de la humanidad, que anida en las grande tradiciones religiosas. La filosofía nos dice en ese texto "no vuelve a empezar cada vez desde el punto cero del sujeto que piensa de manera aislada, sino que se mantiene en el gran diálogo de la sabiduría histórica, que critica y al mismo tiempo dócilmente sigue acogiendo y desarrollando; pero tampoco debe cerrarse ante lo que las religiones, y en especial la fe cristiana han recibido y dado a la humanidad como señal del camino"56 Benedicto XVI nos recuerda que la experiencia histórica nos enseña que la razón, en su debilidad existencial, debe ser ayudada y "curada" por la fe, para que de ese modo puede "llegar a ser totalmente ella misma", como indica en su encíclica Spe salvi. Sin negar el carácter laico del Estado, ni la autonomía de la razón y de la moral, y la libertad de conciencia, la fe puede ayudar a purificar la razón de su "ceguera ética" deslumbrada por determinados intereses y el poder. La razón y la fe se necesitan, pues "la razón sin la fe no sanará, pero la fe sin la razón no será humana". "Las cosas no pueden ser de otra manera: la razón y la religión tienen que volver a acercarse la una a la otra, sin disolverse recíprocamente"57. Esto es algo que puede darse de un modo mucho más factible en el ambiente de diálogo respetuoso y enriquecedor con el que se identifica la laicidad positiva e incluyente. Y el que el Papa resalte las insuficiencias existenciales de la razón, ciertos principios éticos irrenunciables, y la ayuda que puede aportar la fe en la lucha contra el sufrimiento y la injustica, no significa volver a reconfesionalizar la política, sino intentar hallar puntos de encuentro, y una racionalidad común o compartida, por ejemplo sobre el bien común. Es cierto que cuando Benedicto XVI recomienda el fundamento cristiano para avivar y fortalecer el ethos y guiar la razón, lo hace en su condición de teólogo y pastor, y no de filósofo en exclusiva. Es una convicción que se alimenta de su propia experiencia intelectual, pero también religiosa. De lo que se trata es de que, respetando la autonomía de la razón y de las instituciones políticas, la Iglesia, como institución de la sociedad

56 BENEDICTO XVI, "Mantener despierta la sensibilidad a la verdad". (Cf www.revistaecclesia.com).

57 Cfr. RATZINGER, J., Fe, verdad y tolerancia, Salamanca, 2005, pp. 120-121, 128, 222; BENEDICTO XVI, Dios es amor, Madrid, 2006. pp. 46-47. 
civil, pueda ayudar a los hombres a encontrar puntos de encuentro, a vencer los males de este mundo, y a orientar testimonialmente a los poderes públicos, en su intento incesante por mejorar la justicia y el bienestar de los ciudadanos ${ }^{58}$.

Creemos que las tesis defendidas por J. Habermas, Ch. Taylor, y Benedicto XVI, sobre el protagonismo social y moral de las religiones, en el contexto de una laicidad positiva, nos hacen caer en la cuenta de que hay convicciones religiosas, que junto con otras no religiosas, pueden coadyuvar a la vida democrática. Y resultan muy oportunas, contemplando la crítica situación de nuestro país. En este sentido, como afirma el sociólogo de la religión Díaz-Salazar, los españoles estamos necesitados de "tradiciones fuertes de sentido", que se pueden encontrar, entre otras fuentes, en las religiosas ${ }^{59}$. Pienso que enemigos letales de la democracia son la pobreza, la ignorancia y la corrupción, y en una u otra medida, ellas aquejan a nuestra degradada democracia. La corrupción, al servicio de la "partitocracia", puede, hasta cierta medida, manipular y engañar a un pueblo pobre e ignorante. Una "partitocracia" a la que le interesa no la prosecución del bien común, sino el poder y sus prebendas, que practica un pragmatismo cínico e inmoral que tiene que ver con el clientelismo, y que pone al marketing electoral al servicio de sus intereses, que nada o poco tienen que ver con los de la ciudadanía. Para paliar esta grave situación, y en sintonía con el planteamiento de Habermas y de Benedicto XVI, es urgente promover una regeneración moral de nuestra sociedad. Tarea que debería asumir la sociedad civil, que por medio de sus mediaciones (movimientos sociales, ONGS, voluntariados, asociaciones civiles y religiosas...) tiene que promover una opinión pública crítica y un potencial ético. El reciente e "inesperado" movimiento del 15-M y la "Spanish Revolution", más allá de otros posibles análisis que puedan hacerse del mismo, es un claro índice de la crispación indignada, y de la desesperación de sectores sociales muy afectados por una crisis, que se ceba especialmente en nuestra juventud. Por ello, no es de extrañar el éxito editorial que ha tenido en nuestro país, la publicación del folleto de Stéphane Hessel60. En este contexto, la institución religiosa y sus protagonistas deberían de ser conciencia crítica frente a un sistema de partidos, que muchas veces manipula y engaña a la sociedad en vez de servirla Ante esta situación preocupante, la responsabilidad de los

58 Cfr. RATZINGER, J., Verdad, valores, poder, Madrid, 2005; pp. 104; FERNÁNDEZ DEL RIESGO, Manuel, op. c it., 2010, pp., 127-137.

59 Cfr. DÍAZ-SAlAZAR, R., España laica. Ciudadanía plural y conciencia nacional, Madrid, 2008, pp. 171, 226.

60 HeSSEL, Stéphane, iIndignaos!, Barcelona, 2011. 
creyentes de cara asumir su testimonio profético, en el contexto de la laicidad positiva, es algo evidente y urgente. En este sentido, estimo oportuno recordar aquí el testimonio de un intelectual y artista norteamericano, que combina el jazz con el mundo de las ideas: Cornel West, al que ya antes hemos citado. Él ha insistido en la dimensión profética de la fe judeocristana. Algo que tiene que ver con su "experiencia afroamericana", y que conecta con un análisis de la "explotación social" de orden racial, de género y de clase. La religión nos ayuda a mantener a raya la tentación del absurdo con sus anhelos utópicos, sin que nos evite asumir lo trágico de la vida, y a estar en solidaridad con los miserables de la sociedad y con su mundo, esto es con su modo de enfrentarse a su difícil situación ${ }^{61}$. Ese giro profético fue un invento judío, que encierra una revolución ética en la historia de la humanidad, que no deberíamos olvidar. Se atreve incluso a afirmar: "En cierto modo, aun nuestros discursos morales seculares no son más que profusas notas al pie de esa página". Lo profético como "amor y disposición a celebrar con los que sufren y trabajar a su lado", y que está siempre "lleno de justa indignación y santa ira contra la injusticia". E insiste: “ ¿podemos imaginar un discurso público sin que haya voces -no sólo ecos: voces -que alerten de lo catastrófico, para que las élites encumbradas e irresponsables no causen estragos con su codicia y su empatía estrecha y su imaginación truncada?". Frente a las religiones adaptadas al sistema social, y por tanto "adaptadas la indiferencia del satu quo por los pobres y los trabajadores", la "profética" "es una praxis performativa, individual y colectiva, de inadaptación a la codicia, al miedo y al fanatismo ${ }^{62}$.

\section{Los posibles "desencuentros"}

El Estado y las instituciones religiosas no tienen la misma naturaleza, ni tienen idénticas funciones, pero inevitablemente acaban encontrándose en algunos "campos de actuación". Ahora bien, el alcance de la obligatoriedad de la ética civil y de la moral religiosa no es el mismo. La segunda

61 Cfr. MENDIETA, Eduardo. VANANTwerPen, Jonathan, "Introducción". En HABERMAS, Jürgen. TAYLOR, Charles. BUTLER Judith. WEST, Cornel, op. cit., pp. 19-21; WEST, C. La evasión americana de la filosofía: una genealogía del pragmatismo, Madrid, 2008 , cap. 6.

62 WEST, Cornel, "Religión profética y futuro de la civilización capitalista" En HABERMAS, Jürgen. TAYLOR, Charles. BUTLER, Judith. WEST, Cornel, op. cit., pp. 90, 91, 93. 
afecta a la intimidad de la conciencia personal, que el Estado deberá, en principio respetar, teniendo como límite esa ética civil a la que hemos hecho referencia. En cambio ésta última tiene un alcance o proyección jurídica, en determinadas normas de convivencia que el Estado protege, incluso con el derecho penal. La moralidad pública se ve reforzada por la obligatoriedad jurídica, en pro del bien común y la cohesión social. Claro que hay que entender que hay derechos establecidos por el poder político (derecho positivo), que como posibilidades opcionales, no tienen por qué ser asumidos necesariamente por todos los ciudadanos. Sólo así se respeta la objeción de conciencia, que acompaña a la propia dignidad y libertad personales. (Por ej.: el "derecho" al aborto).

El problema está en que, a partir del acuerdo de que la soberanía política descansa en la dignidad humana, pueden originarse desacuerdos a partir de las distintas modos de concebir, en último término, qué sea la persona humana, y su plena realización. Esto tiene que ver con saberes últimos sobre la existencia y la hipotética felicidad humanas. Por ello puede ocurrir que, en la interpretación y aplicación práctica de determinados derechos, en un caso determinado, no nos pongamos de acuerdo. (Ej.: la tensión ético-jurídica que se da entre los principios generales del derecho y el respeto a la vida humana y a la libertad, y la posible legislación sobre la eutanasia). Es legítimo que todos los ciudadanos aspiren a que la normativa que el Estado consensue, en un momento determinado, se adecue a sus ideales y principios, que creen verdaderos y mejores. Pero si no lo consiguen, ello no debe llevar, en principio, a posturas intolerantes, que desautoricen o rechacen la soberanía ciudadana, que reside en el parlamento de la nación, y la propia democracia. Naturalmente salvo casos excepcionales, en que el poder legislativo o el ejecutivo atente clara, y gravemente contra los principios constitucionales, y la ética civil o de mínimos, traicionando al mismo Estado de los que son partes constituyentes. Es entonces la hora de la "desobediencia civil". Pero salvando esta excepción límite, en la que, ante el atentado grave a la dignidad humana se impone la "sana "intolerancia" (ej.: la ablación genital femenina, la lapidación, la amputación, la violencia de género, la xenofobia, la masacre de una sociedad civil indefensa, etc.), el libre juego político, y el debate de la sociedad civil, siguen estando abiertos a futuras rectificaciones. Sólo al laicismo negativo y excluyente, que pretende heterodirigir de modo intolerante, le resulta incómodo el protagonismo social de la religión, en este libre juego de las libertades.

Ya he comentado en más de una ocasión, que el auténtico ciudadano demócrata es el "constante insatisfecho". En una sociedad plural y compleja, como la nuestra, es necesario asumir el riesgo del debate en la sociedad 
civil, con todos sus agentes, incluidos los religiosos. Ello puede ayudar a vertebrar, en una tarea siempre perfectible, el binomio libertad-verdad, sin caer en fundamentalismos. En este sentido, tiene razón el profesor Fernando Savater ${ }^{63}$, cuando afirma que la autoridad democrática de la razón deberá ser el camino hacia la verdad. Los demócratas serán los ciudadanos razonables, y no los serán, quienes carezcan de la capacidad de aceptar, el argumento de mayor poder de convicción, venga de quien venga, de cara a consensuar la mejor solución posible, con relación a una determinada problemática de interés social. Es necesaria, por tanto, la razón dialógica y democrática, para legislar con el máximo consenso que se pueda, aunque la solución no guste a todos por igual. Insisto, es cierto que la vertebración legal del bien común, que el Estado, pueda alumbrar con relación a una cuestión problemática, puede implicar ciertas desaveniencias con la manera de interpretarla y evaluarla de una confesión religiosa, orientada por sus concepciones antropológicas, éticas y espirituales, o con la de otra concepción de naturaleza secular. Pero la gran ventaja de la sociedad democrática es que la legislación vigente no es inamovible, y puede quedar abierta, en un futuro, a una posible rectificación y perfeccionamiento, gracias a ese constante diálogo entre la sociedad civil y el Estado. Naturalmente esto puede engendrar, a veces, ciertas tensiones y discusiones, pero ello es el coste y el único camino para alumbrar soluciones cada vez más consensuadas, con la intención y la eseranza de alcanzar modos de proceder cada vez más razonables ${ }^{64}$.

Lo que no se puede olvidar, frente a los fundamentalismos, ya sea el religioso (integrismo) o el laico (laicidad negativa), es que son expresiones de un "despotismo", que despoja a la mayoría de los ciudadanos de su corresponsabilidad política, en la tarea de fraguar un proyecto comunitario, y ello, además, entendido como un proceso histórico siempre abierto a la revisión crítica. El fundamentalismo, en su pretendida posesión definitiva de una verdad absoluta y excluyente, que le legitima para imponerla de un modo coactivo, o disimulado, es incompatible con la dignidad del ciudadano demócrata, pues olvida una distinción clavel: la posible sujeción a una norma jurídica que se fundamente en el poder persuasivo de la razón argumental es compatible, y expresión de la dignidad y libertad ciudadanas, pero en cambio nunca lo podrá ser la sujeción a la voluntad del otro, por cualificado y bienintencionado que sea. El humanismo democrático no casa bien con el paternalismo despótico, que pretende imponer el bien y la

63 SAVATER, Fernando, Las preguntas de la vida, Barcelona, 1999.

64 Cfr. FERNÁNDEZ DEL RIESGO, Manuel, op. cit., 2010, pp. 142-55. 
libertad. Es cuestionable "obligar" a la gente a ser libre y justa. En este sentido, no nos cansamos de repetir que, por paradójico que parezca, una enseñanza de la propia experiencia histórica, es que en el diálogo, como instrumento epistemológico, el error transitorio ha sido en muchas ocasiones, y lo seguirá siendo, un coste que se ha pagado y se continuará pagando, en la prosecución inagotable hacia la verdad y la justicia. Esta aventura se escribe, en muchas ocasiones, mediante "renglones torcidos"

Cuanto más dinámica y participativa sea la sociedad civil, habrá más oportunidades de que los poderes políticos y su ordenamiento jurídico sintonicen con las necesidades y expectativas ciudadanas, y se consiga de ese modo una sociedad más justa, e integrada. Si este espíritu de la secularidad o laicidad positiva acabase por predominar en nuestra sociedad en general, $\mathrm{y}$, especialmente, en el debate político, y en el diálogo entre el estado y las instituciones religiosas, muchos de los malentendidos y enfrentamientos podrían superarse de modo más razonable. 